$\mathbb{P}$ periodica polytechnica

Transportation Engineering $41 / 2(2013) 87,94$

doi: 10.3311/PPtr.7107

http://periodicapolytechnica.org/tr

Creative Commons Attribution (i)

RESEARCH ARTICLE

\section{Complex Process Monitoring of Cutting Hybrid Metal Structures}

Ferenc Dömötör / Balázs Vehovszky / Zoltán Weltsch / Szilárd Németh / György

Terpó

Received 2013-09-04

\begin{abstract}
The behavior of the cutting edge of the tool during the cutting process, especially the impact of the boundary surfaces of different materials has been studied by several authors. In this paper the latest results, achieved by our team, are reported. Several methods of the complex diagnostics of the cutting process of metal composite structures, including cutting force measurement, vibration analysis, high speed camera and thermography were successfully used for this purpose. It was found, that the boundary surface of the different materials has a big impact on the cutting force, the vibration and the temperature of the tool, which can be monitored very effectively with this complex technique.
\end{abstract}

\section{Keywords}

process monitoring $\cdot$ hybrid materials $\cdot$ cutting force measurement $\cdot$ thermography $\cdot$ vibration diagnostics

\section{Acknowledgement}

The authors wish to express their thanks to the NIH (National Innovation Office, Budapest) for their support by the project „K+F Munkaero_09”. Also we highly appreciate the contribution of the companies Gamax Laboratory Solutions Kft., KnorrBremse Hungária Kft. and SKF Svéd Golyóscsapágy Rt. to the measurements and data processing.

\section{Ferenc Dömötör}

Department of Automobiles and Vehicle Manufacturing, Budapest University of Technology and Economics, Stoczek u. 4., H-1111 Budapest, Hungary e-mail: domotor@kgtt.bme.hu

\section{Balázs Vehovszky}

\section{Zoltán Weltsch}

Department of Automobiles and Vehicle Manufacturing, Budapest University of Technology and Economics, Stoczek u. 4., H-1111 Budapest, Hungary

\section{Szilárd Németh}

Gamax Laboratory Solutions Kft., Bartók Béla út 15/d., H-1114 Budapest, Hungary

\section{György Terpó}

SKF Svéd Golyóscsapágy Rt., Csata u. 25., 2040 Budaörs, Hungary

\section{Introduction}

The Department of Automobiles and Vehicle Manufacturing of BME some years ago as a partner of an EU sponsored project (2004-2006) took part in the research project of the investigation of economically and environmentally friendly cutting process. The results have been published in several reports by Ozsváth et al. [6,7] and Dömötör et al. [1-5]. Encouraged by the success of the project it seemed to be advisable to develop the results towards the complex diagnostics of the technology. In this stage of the project the vibration measurement data together with the thermo camera and high speed camera pictures are presented. Also the cutting force has been measured and the data were processed by the MatLab software. It was found, that the boundary surface of the different materials has a big impact on the various parameters, which can be monitored very effectively with this technique.

\section{The cutting process}

The investigated process was an orthogonal cutting on a lathe, located in our laboratory. The test rig used for the measurements can be seen on Fig. 1

The main parameters of the cutting were as follows:

- speed of the spindle: $n=265 \mathrm{rpm}$,

- feed rate: $0.0125 \mathrm{~mm} /$ rotation,

- width of the rim (cut): $3 \mathrm{~mm}$.

The tool itself was a Mircona-1 L151S-2525x20x5-EB holder, and an SHL 205 HT cutting insert.

\section{Preparation of the samples to be tested}

The purpose of our research was to monitor the main parameters of the transient process, when the tool passes the contact surface of the hard-soft and soft-hard components. For this a special "hot dog" type specimen was developed. The cylinder was made of aluminium alloy AlMgSi1F30, and the thorn was made of C45 steel. Diameter of the Al cylinder is $\varnothing 110 \mathrm{~mm}$, while that of the $\mathrm{C} 45$ bar was $\varnothing 22 \mathrm{~mm}$ before turning (see Fig. 2).

In order to provide plugs with different hardness, heat treatment methods were applied. The 5 plugs were quenched at the 
Fig. 1. Setup of the testing equipment and instruments

Fig. 2. Specimens of the experiment

Fig. 3. Micro hardness of the thorns of the different specimens ( $\mathrm{Nr} 3, \mathrm{Nr} 32, \mathrm{Nr} 33, \mathrm{Nr} 34$, and $\mathrm{Nr} 35)$
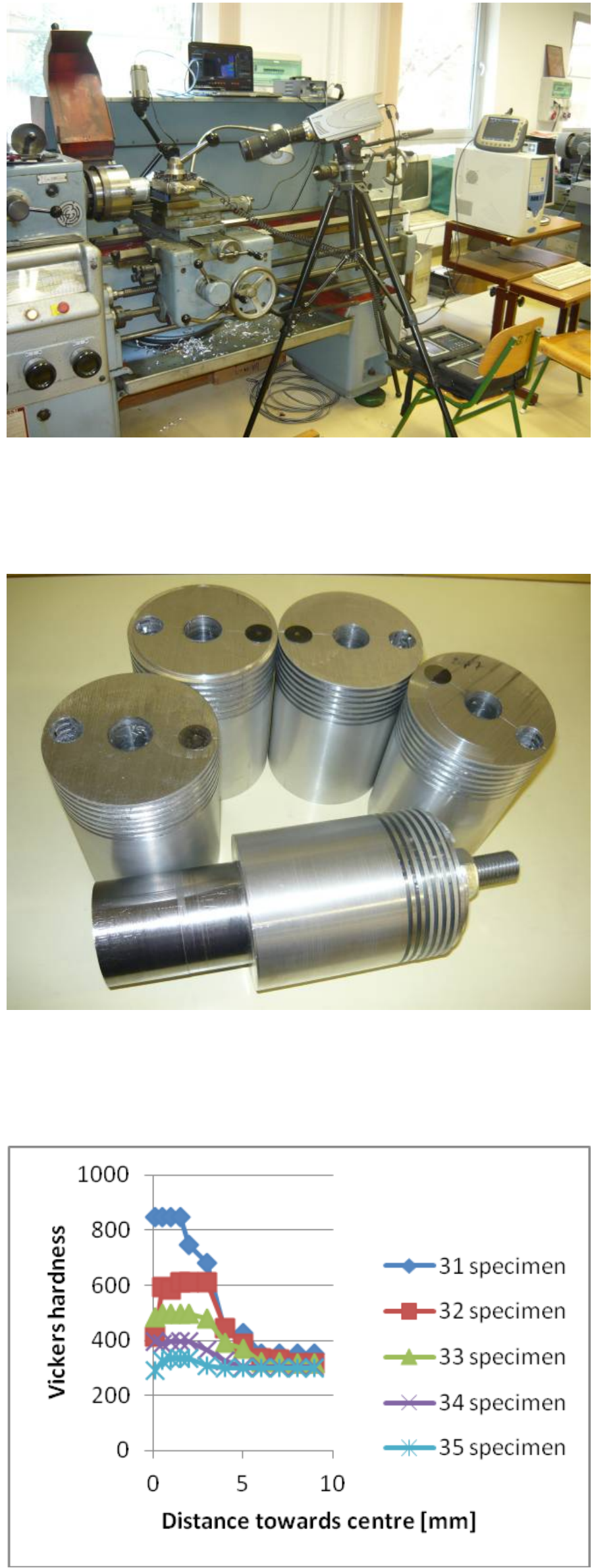
same conditions, and afterwards tempered for 1 hour at $T=100$, $200,300,400$ and $500{ }^{\circ} \mathrm{C}$ temperature, respectively. Plugs were fitted into the aluminium cylinders by heat shrinkage method.

Micro hardness of the thorns was determined by the so called indentation method, using a Hanneman type equipment. The force applied was $1 \mathrm{~N}$, while for the hardness measurements the Vickers method was used. As it is obvious from the Fig. 3 the hardness of the thorns are different in the range of radius $0,5-6$ $\mathrm{mm}$ from the outer surface of the cylinder towards the centre.

\section{Cutting force measurement and data processing by the Matlab software}

The cutting was measured by a KISTLER 9257A type 3 Component Dynamometer. Sampling of the analogue data was carried out by a speed of $10 \mathrm{kHz}$. After using an A/D converter the digital data were processed and monitored by the MatLab software.

Where the probe is theoretically homogenous (alloyed aluminum), there no special impact can be seen on the diagram, and so it is nearly flat.

However, where the tool hits the hole, there the cutting force becomes zero. On the other hand, when the tool hits the hard thorn, then in this case a strong shock pulse can observed (Fig. 5) on the time signal.

\section{Vibration measurement}

For the vibration measurements a CMVA60 vibration analyser and data collector, made by SKF has been used. The measured vibration parameter - among others - was the so called Enveloped Acceleration (ENV1). The CMSS 2200 type accelerometer was also made by SKF. It has $100 \mathrm{mV} / \mathrm{g}$ sensitivity. Input and spectrum setup parameters were as follows: frequency range: 1-400 Hz, resolution 3200 FFT lines, average number 1, Peak to Peak, Hanning window.

All these diagrams (Fig. 7, 8, 9) are a proof on the strong influence of the thorn hardness. The harder the thorn, the higher the amplitude of the impact.

\section{Measurements by the thermo camera}

Thermal pictures have been taken by a FLIR A325 camera. Naturally, only relative temperature can be seen on the pictures, because the emission factors could not be determined exactly. Moreover, an exact emission factor does not exist, because of the different optical features of the hybrid material. Consequently, the temperature values are only relative values.

As a result of the measurement it can be seen, that the temperature of the chips is changing between $50{ }^{\circ} \mathrm{C}$ and $350{ }^{\circ} \mathrm{C}$. Also it can be observed, that there is a certain periodicity of the temperature variation, although the sampling frequency (Shannon rule) is certainly not enough to get a proper picture.

On the other hand, the temperature of the tool also depends on the hardness of the plugs. As shown on the Fig. 11 the extremely hard plug $\left(\mathrm{Nr} 31\right.$, tempered at $100{ }^{\circ} \mathrm{C}$ only) has a strong influence on the tool temperature, which is changing periodically. The softest plug on the other hand has practically no influence on the tool temperature, which remains nearly constant in time in this case ( $\mathrm{Nr} 35$ specimen).

\section{Pictures, taken by the high speed camera}

A high speed camera of type OLYMPUS i-speed 2 has been used take photos of the process. The main parameters of the high speed camera: colour recording (max. speed: $150000 \mathrm{~F} / \mathrm{s}$ ), max. res.: $1280 * 1024$ pixel. The maximum time interval can be increased up to $180 \mathrm{sec}$ if the resolution is decreased accordingly. For the camera a high powered light source, independent from the frequency, has been used: Olympus, ILP-1.

The formation of the chip can be seen on the Fig. 7 It can be observed, that the chips of different material immediately separate from the specimen, and consequently no continuous chips can be formed during the cutting.

\section{Checking the geometry of the specimens}

After the measurement the geometrical shape of the specimens has been checked. At first the roundness has been checked, and a considerable deviation from the circular shape has been found in all 5 cases (Fig. 14).

Surface parameters have been checked by a MarSurf XCR20 equipment and software. It was found, that the deviation from roundness can be as high as $0.41 \mathrm{~mm}$. On the other hand, the highest values of the surface roughness parameters (Nr34 specimen) were as follows:

$$
\begin{aligned}
R_{a} & =2.227 \mu \mathrm{m} \\
R_{\mathrm{z}} & =7.912 \mu \mathrm{m} \\
R_{\max } & =8.32 \mu \mathrm{m}
\end{aligned}
$$

\section{Metallographic structure of the plugs}

In order to "double check" the mechanical properties of the specimens, a metallographic test has been carried out. Results of the tests can be seen Fig. 18 (martensitic structure, very high hardness) and Fig. 19 (bainit + perlit, definitely lower hardness).

The surface roughness of the Nr34 specimen is extremely spectacular, as it corresponds to a vibration of $3427 \mathrm{~Hz}$ at rotational speed od $265 \mathrm{rpm}$ of the spindle.

\section{Conclusions}

Micro hardness of the plugs of the various specimens (having different heat treatment) is changing along the radius of the plug. The hard thorn is providing a very strong impact (excitation) on the cutting force and consequently on the vibration of the tool as well.

The impact of force can be quite well approximated by the shape of a square function in the time domain and consequently it has the similar pattern (FFT of a square function) in the frequency domain as well. 
Fig. 4. Setup of the KISTLER dynamometer



Fig. 5. Time signal of the force measurement
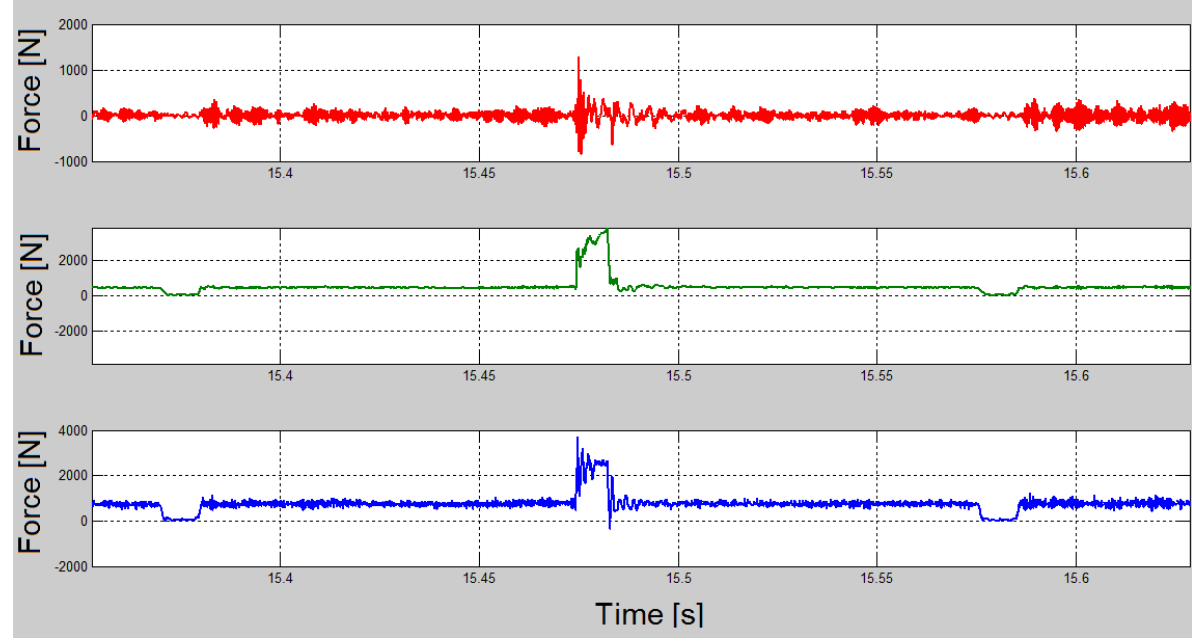

Fig. 6. Spectrum of the force measurement (Impact section of the time signal on Fig. 5 after FFT)

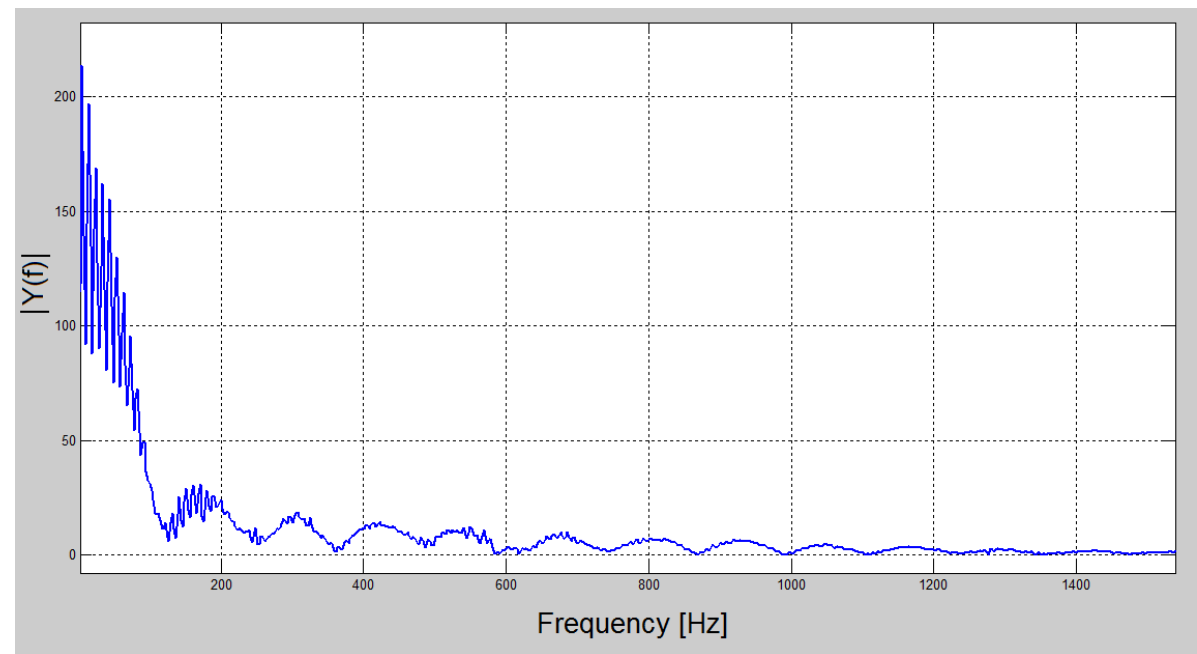


Fig. 7. Palogram of the vibration spectra (Spectra of different specimens - vertical direction)

Fig. 8. Time diagram of the vibration (Vibration velocity, vertical direction $35 \mathrm{~F} 1$ specimen)

Fig. 9. Vibration spectrum (Vibration velocity, vertical direction $35 \mathrm{~F} 1$ specimen)

Fig. 10. Thermal picture of the chips (Temperature vs. time)
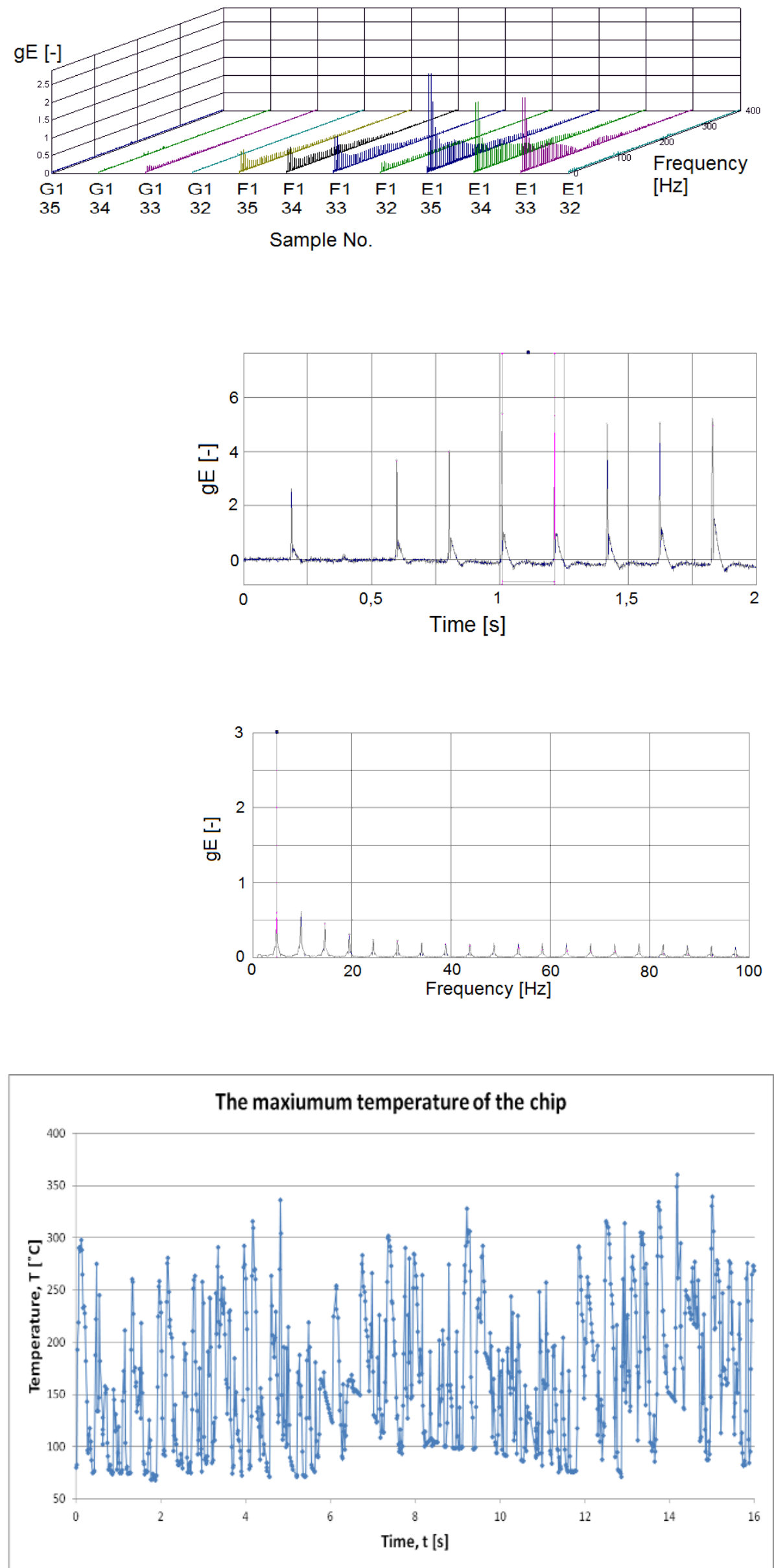
Fig. 11. Temperature of the tool tip when cutting different specimens $(\mathrm{Nr} 31, \mathrm{Nr} 32, \mathrm{Nr} 33, \mathrm{Nr} 34$ and Nr35 respectively)

Fig. 12. Formation of the chip (Picture taken by the high speed camera)

Fig. 13. Formation of the chip when the tool hits the boundary (Picture taken by the high speed camera)

Fig. 14. Deviation of the circular shape of the specimen
Average temperature of the tool at various thorns (31-35)

Fig. 15. Surface roughness of the specimen Nr34

\begin{tabular}{|ll|ll|}
\hline Messgerät: & Mahr-Messkarte & Lt: & $5,6 \mathrm{~mm}[\mathrm{~N}=5]$ \\
Vorschubgerät: & GD 25 & Ls: & $2,5 \mu \mathrm{m}$ \\
Taster: & MFW-250 [3,1\%] & VB: & $\pm 250 \mu \mathrm{m}$ \\
& & Vt: & $0,50 \mathrm{~mm} / \mathrm{s}$ \\
& Punkte: & 11200 \\
\hline
\end{tabular}

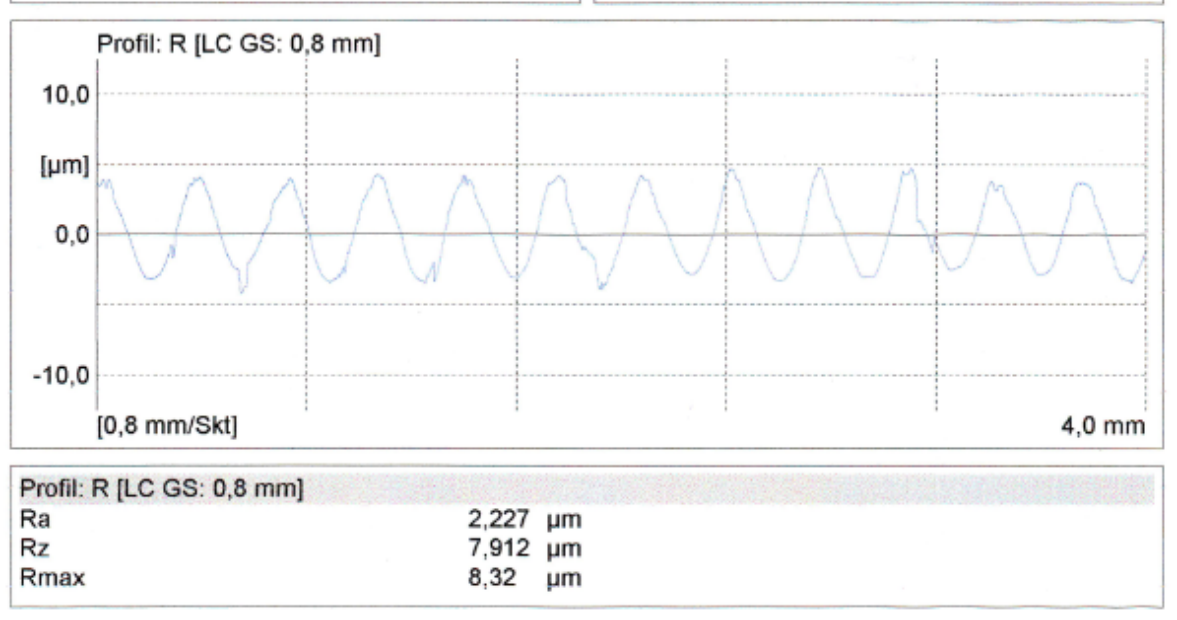

Fig. 16. Surface roughness of the specimen $\mathrm{Nr} 34$

Fig. 17. Specimens, prepared for metallographic testing

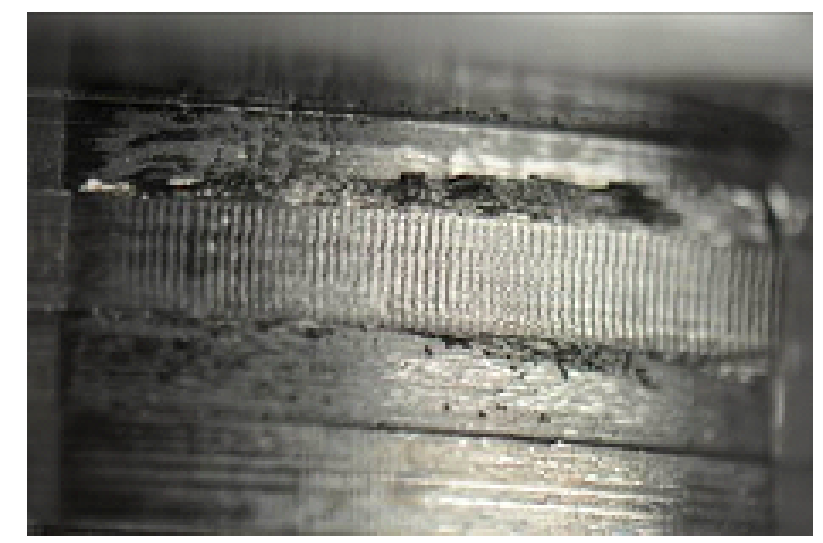


Fig. 18. Metallographic texture of the specimen (Nr1B specimen 500:1 scale)

Fig. 19. Metallographic texture of the specimen (Nr5B specimen 500:1 scale)
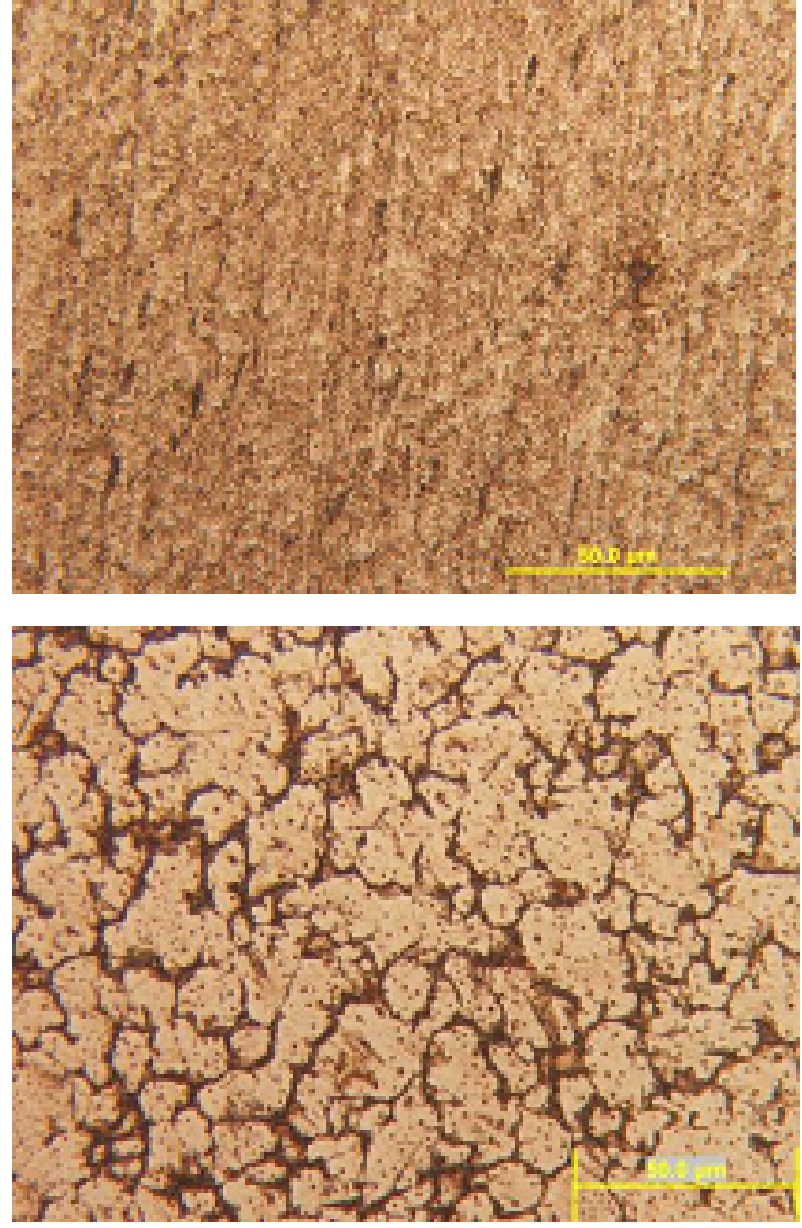

The temperature of the tool is changing with the Vickers hardness of the plug. Moreover, the harder the plug is (Nr31 specimen), the higher the amplitude of the temperature function will be. The tempered thorn causes no fluctuation ( $\mathrm{Nr} 35$ specimen) at all, while the quenched thorn ( $\mathrm{Nr} 31$ specimen) causes a sinusoid like function, where the period of the fluctuation coincides with the period of the time of the rotation of the spindle.

\section{References}

1 Dömötör F, Bánlaki P, Weltsch Z, Complex Diagnostics of Metal Composite Materials. IN-TECH Conference 2011, Bratislava, Slovakia, 2011.

2 Dömötör F, Bánlaki P, Weltsch Z, Some Features of the Complex diagnostics of the Cutting Process of Metal Composite Structures. Danubia-Adria Symposium, 2011, Siófok, Hungary, 2011.

3 Dömötör F, Németh S, Vehovszky B, Some Features of the Complex Diagnostics of Cutting Hybrid Metal Structures. SEMDOK 2011. Conference, Zilina-Terchova, Slovakia, 2011.

4 Dömötör F, Szilágyi A, Weltsch Z, Diagnostic Test of the Cutting Process of Metal Composite Structures, Using Vibration Analysis and Thermo Camera. MicroCAD 2012, Miskolc, Hungary, 2012.

5 Dömötör F, Bauernhuber A, Szabo A, Complex Diagnostics of the Cutting Process of Hybrid Material Structures. . . 29th International Colloquium, University of Zilina, Terchova, Slovakia, 21-23. May, 2012.

6 Ozsváth P, Takács J., Investigation of Hard-soft Boundaries of Mg Based Hybrid Materials, Materials Eng, 15(2a), (2008), 15-22.

7 Ozsváth P, Szmejkál A, Takács J, Dry Milling of Mg Based Hybrid Materials, Periodica Politechnica Transportation Engineering, 36(1-2), (2008), 73-78, DOI 10.3311/pp.tr.2008-1-2.14 